
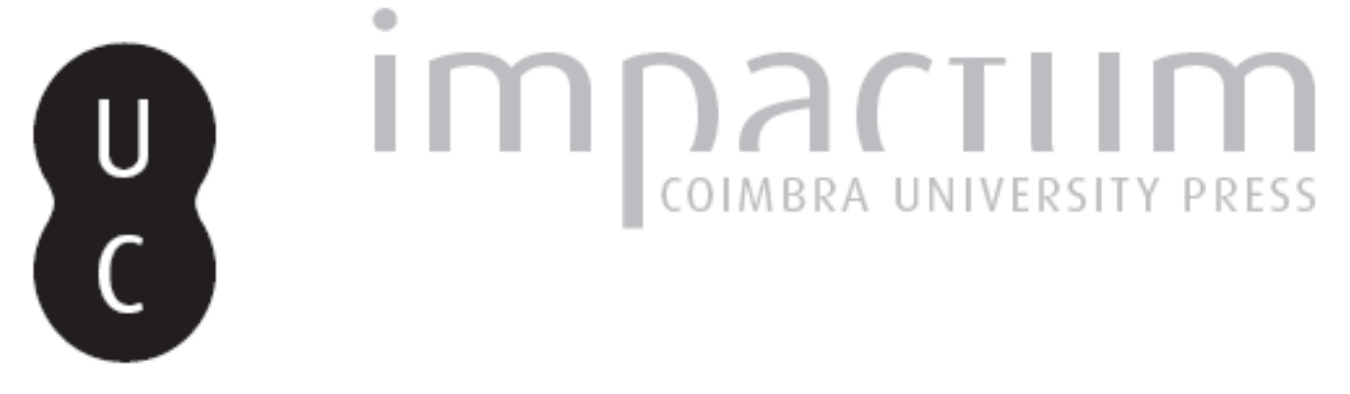

\title{
Riscos vulcânicos: o caso do vulcão do Fogo de Cabo Verde
}

\section{Autor(es): $\quad$ Gomes, Alberto Mota}

Publicado por: Associação Portuguesa de Riscos, Prevenção e Segurança

URL persistente:

URI:http://hdl.handle.net/10316.2/40108

DOI:

DOI:https://doi.org/10.14195/1647-7723_7_1

Accessed : $\quad$ 26-Apr-2023 12:42:37

A navegação consulta e descarregamento dos títulos inseridos nas Bibliotecas Digitais UC Digitalis, UC Pombalina e UC Impactum, pressupõem a aceitação plena e sem reservas dos Termos e Condições de Uso destas Bibliotecas Digitais, disponíveis em https://digitalis.uc.pt/pt-pt/termos.

Conforme exposto nos referidos Termos e Condições de Uso, o descarregamento de títulos de acesso restrito requer uma licença válida de autorização devendo o utilizador aceder ao(s) documento(s) a partir de um endereço de IP da instituição detentora da supramencionada licença.

Ao utilizador é apenas permitido o descarregamento para uso pessoal, pelo que o emprego do(s) título(s) descarregado(s) para outro fim, designadamente comercial, carece de autorização do respetivo autor ou editor da obra.

Na medida em que todas as obras da UC Digitalis se encontram protegidas pelo Código do Direito de Autor e Direitos Conexos e demais legislação aplicável, toda a cópia, parcial ou total, deste documento, nos casos em que é legalmente admitida, deverá conter ou fazer-se acompanhar por este aviso.

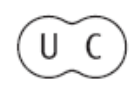




\title{
Riscos vulcânicos. O caso do vulcão do Fogo de Cabo Verde
}

\author{
Alberto Mota Gomes *
}

\begin{abstract}
Resumo:
Após a apresentação do enquadramento geográfico do Arquipélago de Cabo Verde, mostram-se os aspectos geomorfológicos e a estrutura vulcânica e tectónica da Ilha do Fogo. Com base na erupção de Abril de 1995, faz-se em seguida a descrição dos riscos vulcânicos salientando-se os tiscos de contaminação da água para o consumo público, os riscos provocados pela libertação de gases vulcânicos, os riscos de ocupação de áreas por lavas e os riscos sísmicos associados ao vulcanismo.

Palavras chave:

Arquipélago de Cabo Verde, Ilha do Fogo, Riscos vulcânicos.

Résumé:

Après la présentation du cadre géographique de l'Archipel du Cap Vert, l'auteur montre les aspects géomorphologiques et la structure volcanique et tectonique de l'île du Fogo. À la suite, ayant l'éruption du mois d'Avril 1995 comme exemple, il fait la description des risques volcaniques en mettant l'accent sur les risques de contamination de l'eau potable, les risques provoqués par la libertation de gaz volcanique, les risques d'occupation de terrains par coulées de laves et les risques seismiques associés au volcanisme.

Mots clés:

Archipel du Cap Vert, Île du Fogo, Risques volcaniques.

\section{Abstract:}

After the geographical presentation of Cape Verde Archipelago, the author shows the geomorphological aspects and the volcanic structure and tectonics of Fogo Island. Then, based on the eruption of April 1995, he describes the volcanic hazards, specially concerning water pollution, volcanic gases, lavas and related seisms.

Key words:

Cape Verde Archipelago, Fogo Island, Volcanic hazards.
\end{abstract}

\section{Enquadramento do Arquipélago de Cabo Verde}

\section{Origem e localização}

As ilhas de Cabo Verde elevam-se de um soco submarino, em forma de ferradura, situado a uma profundidade da ordem dos 3000 metros. Deste soco emergen três pedestais bem distintos (J.B.BEBIANO, 1932). O do Norte compreende as Ilhas de Santo Antão, São Vicente, Santa Luzia e São Nicolau, e os ilhéus Boi, Pássaros, Branco e Raso. O de Leste e Sul tem as Ilhas do Sal, Boa Vista, Maio e Santiago e os ilhéus Rabo do Junco, Curral de Dadó, Fragata, Chano, Baluarte e de Santa Maria. O de Oeste compreende as Ilhas do Fogo e Brava e os ilhéus Grande, Luís Carneiro e de Cima (Fig. 1).

* Geólogo. Professor do Instituto Superior de Educação, Praia, Cabo Verde.
O Arquipélago de Cabo Verde fica localizado na margem oriental do Atlântico Norte, a cerca de 450 Km da costa ocidental da África e a cerca de 1400 $\mathrm{Km}$ a SSW das Canárias, limitado pelos paralelos $17^{\circ} 13^{\prime}$ (Ponta Cais dos Fortes, Ilha de Santo Antão) e $14^{\circ} 48^{\prime}$ (Ponta de Nho Martinho, Ilha Brava), de latitude Norte, e pelos meridianos de $22^{\circ} 42^{\prime}$ ' (ilhéu Baluarte, Ilha da Boa Vista) e $25^{\circ} 22^{\prime}$ (Ponta da Chã de Mangrado, Ilha de Santo Antão) de longitude Oeste de Greenwich.

O Arquipélago de Cabo Verde fica situado a cerca de $2000 \mathrm{Km}$ a Leste do actual "rift" da "Crista Média Atlântica" (L. C. SILVA, 1992) e a Oeste da "zona dequietude magnética" ("quite zone")entre as isócronas dos 120 e dos 140 M.A., segundo VACQUIER (1972, cit. por L. C. SILVA), e as dos 107 e dos 153 M.A., segundo HAYNES e RABINOWITZ (1975, 


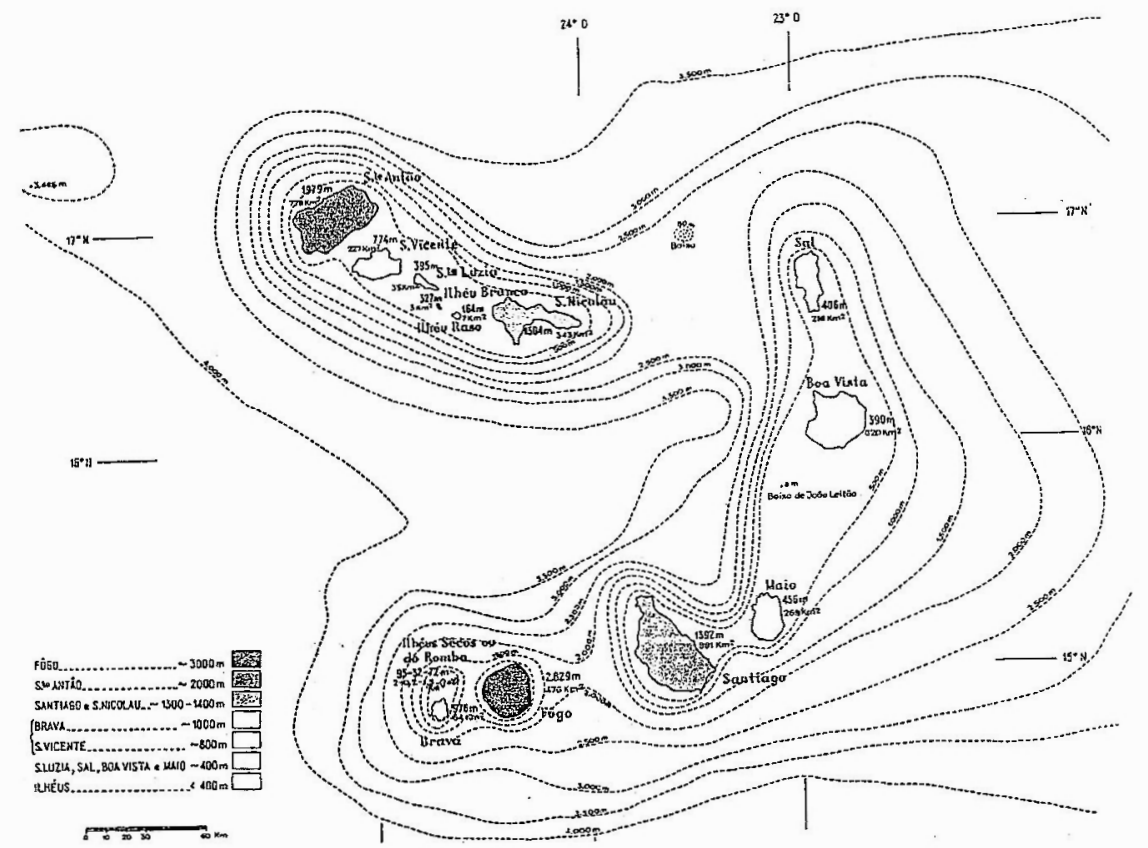

Fig. I - Mapa de Cabo Verde e sua distribuiçãa pelos três pedestais. Adaptado de J.B. BEBIANO (1932). cit. igualmente por L.C. SILVA), argumentos invocados para se considerar que as ilhas teriam sido geradas em ambiente oceânico.

O Arquipélago de Cabo Verde encontra-se numa região elevada do actual fundo oceânico que faz parte da "Crista de Cabo Verde" ("Cape Verde Rise") e que na vizinhança das ilhas corresponde a um domo com cerca de $400 \mathrm{Km}$ de largura (LANCELOT et al., 1977, cit. por L.C. SILVA, 1992). Presume-se que um domo destas dimensões representa um fenómeno importante, possivelmente relacionado com descompressão e fusão parcial (LE BAS, 1980, cit. por L. C. SILVA) que forneceria a fonte dos magmas que originaram as ilhas (STILLMAN et al., 1982, cit. também por L. C. SILVA). De acordo com alguns autores, as ilhas ter-se-iam implantado por um mecanismo do tipo "hot-spot".

\section{Geomorfologia}

O Arquipélago de Cabo Verde compõe-se de dez ilhas e treze ilhéus que, devido à sua posição relativa aos ventos alísios, dominantes, que sopram de Nordeste, se consideram divididos em dois grupos - Barlavento e Sotavento (Fig. 2). O Grupo de Barlavento é formado pelas ilhas de Santo Antão, S. Vicente, Santa Luzia, S. Nicolau, Sal e Boavista e os ilhéus Boi, Pássaros, Branco, Raso, Rabo de Junco, Curral do Dadó, Fragata, do Chano e Baluarte. O Grupo de Sotavento é formado pelas ilhas de Maio, Santiago, Fogo e Brava e os ilhéus de Santa Maria, Grande, Luís Carneiro e de Cima.
O Arquipélago de Cabo Verde apresenta um relevo importante que tem como característica orográfica predominante a existência de cadeias montanhosas, notáveis aparelhos vulcânicos bem conservados, numerosos e extensos vales muito encaixados e profundos, nas ilhas montanhosas, com grandes zonas aplanadas apenas nas ilhas do Maio, Sal, Boa Vista e Santa Luzia.

Consideram-se ilhas de relevo acidentado as que têm altitudes máximas acima dos 1000 metros tais como o Pico do Vulcão, na ilha do Fogo, com 2829 metros, o Tope da Coroa, na ilha de Santo Antão, com 1979, o Pico da Antónia, na ilha de Santiago, com 1392, e o Monte Gordo, na ilha de S. Nicolau, com 1304. A ilha Brava, com uma altitude máxima de 976 metros, no Monte Fontaínhas, tendo em consideração a sua área de $64 \mathrm{Km}^{2}$, poderá também considerar-se de relevo acidentado.

Contrariamente, as chamadas ilhas orientais ou planas (Sal, Boa Vista e Maio) e a ilha de Santa Luzia apresentam um relevo suave, podendo-se observar extensas zonas aplanadas, como são exemplos a Terra Boa, na ilha do Sal, a Vila de Sal Rei, na ilha da Boa Vista e as Terras Salgadas, na ilha do Maio. As suas elevações máximas são bem modestas, relativamente às ilhas acidentadas, o que se poderá comprovar pelas suas altitudes máximas - Monte Penoso, na ilha do Maio, com 436 metros, Monte Grande, na ilha do Sal, com 406, e Monte Estância, na ilha da Boa Vista, com 387. A ilha de S. Vicente considera-se de posição intermediária, pois tem altitude máxima de 725 metros. A ilha de Santa Luzia tem como altitude máxima de 395. 
As rochas vulcânicas básicas, com claro predomínio das basálticas e do material piroclástico associado caracterizam a geomorfologia das ilhas.

\section{A ilha do Fogo}

\section{Aspectos geomorfológicos}

A ilha do Fogo fica situada entre os $14^{\circ} 48^{\prime}$ e os $15^{\circ} 3^{\prime}$ de latitude Norte e entre os $24^{\circ} 18^{\prime}$ e os $24^{\circ} 31^{\prime}$ de longitude Oeste de Greenwich. Geomorfologicamente, é um grande aparelho vulcânico complexo, ainda activo, que apresenta a forma de um tronco de cone dissimétrico, centrado a Nordeste; os seus flancos, particularmente abruptos a Leste, apresentam-se menos inclinados a Oeste e a Sul (O. RIBEIRO, 1960). Sobre os flancos desta portentosa montanha, principalmente na base e a meia encosta, observamse cones adventícios de altura variando entre 50 e 100 metros. No topo do aparelho primário, ou seja, na própria ilha, abre-se para Leste uma imensa caldeira, cujo diâmetro maior atinge $8 \mathrm{Km}$.

Com uma forma arredondada, a ilha ocupa uma superfície de $476 \mathrm{Km}^{2}$, com o comprimento máximo de 26300 metros, entre as Pontas Fio de Monte
Vermelho, a Norte, e Montado, a Sul, e a largura máxima de 23900 metros, entre o Porto Vale dos Cavaleiros, a Oeste, e a Ponta do Bombardeiro, a Leste (Fig. 3). O seu relevo é bastante acidentado e nele se distinguem dois troncos de cone: um exterior, que recebe o nome de Serra ou Bordeira, cujo ponto mais alto é o Monte Liso da Fonte, com 2700 $m$ de altitude, outro interior, que compreende a Chã das Caldeiras e o Vulcão.

A Chã das Caldeiras constitui uma imensa caldeira, onde é suave a topografia sendo a planicidade interrompida por alguns cordões de lava. Há nesse fundo um desnível de cerca de 50 metros devido a um degrau transversal que separa os aglomerados populacionais da Bangaeira e da Portela. Todavia, o desnivel entre os cumes da Bangaeira e a Chã das Caldeiras (fundo da caldeira) pode alcançar 800 a 1000 metros.

Do fundo da Chã das Caldeiras ergue-se um aparelho secundário denominado Vulcão, que se eleva cerca de 1100 metros. O seu topo tem a cota mais alta da ilha $(2829 \mathrm{~m})$ e de todo o país. Este ponto faz parte do rebordo de uma cratera com um diâmetro de 500 metros e com 100 a 200 metros de profundidade, consoante a altura do seu bordo desmantelado.

O cone vulcânico secundário ou Vulcão é um gigantesco cone de cinzas e de escórias com episódios

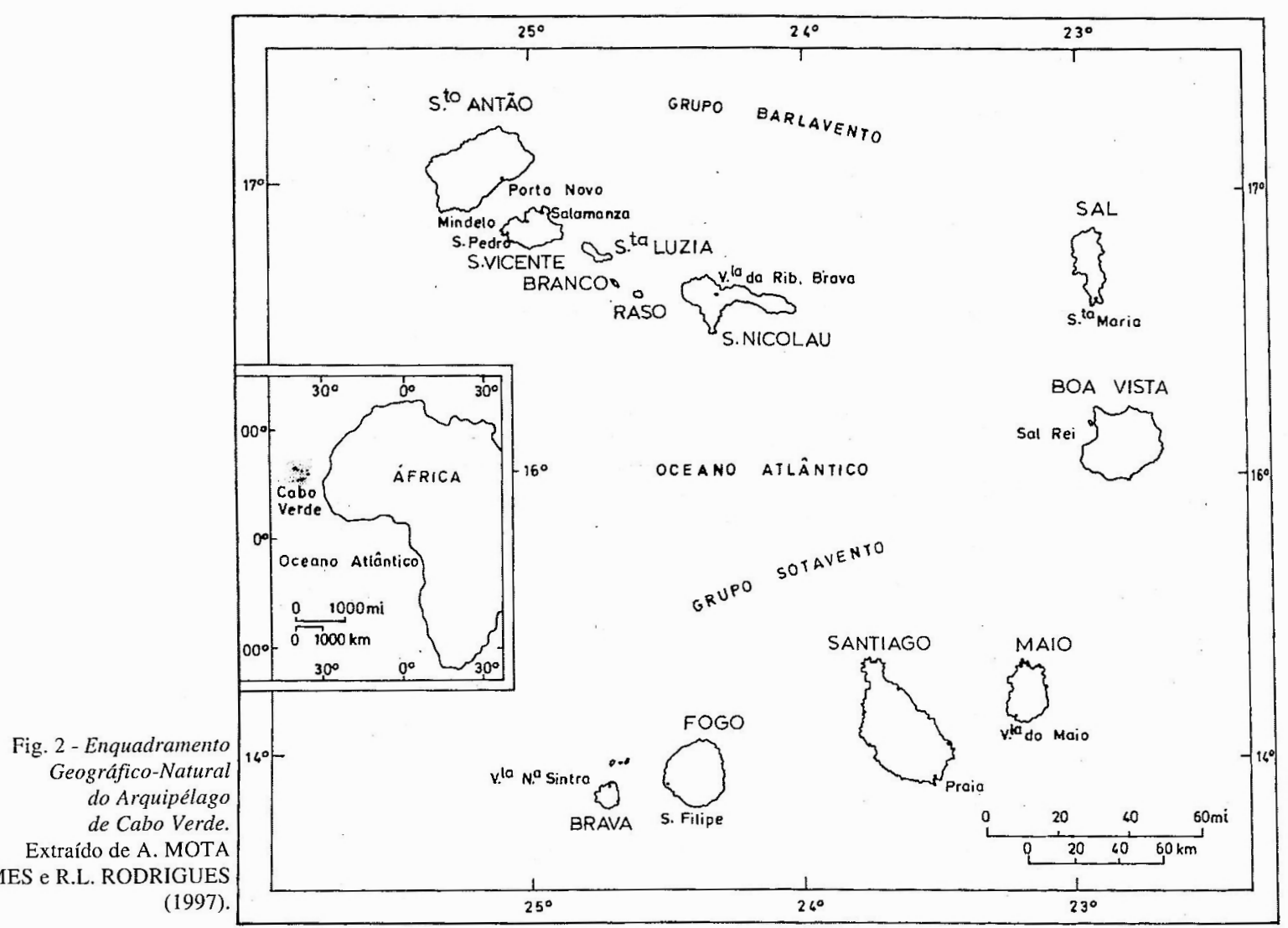




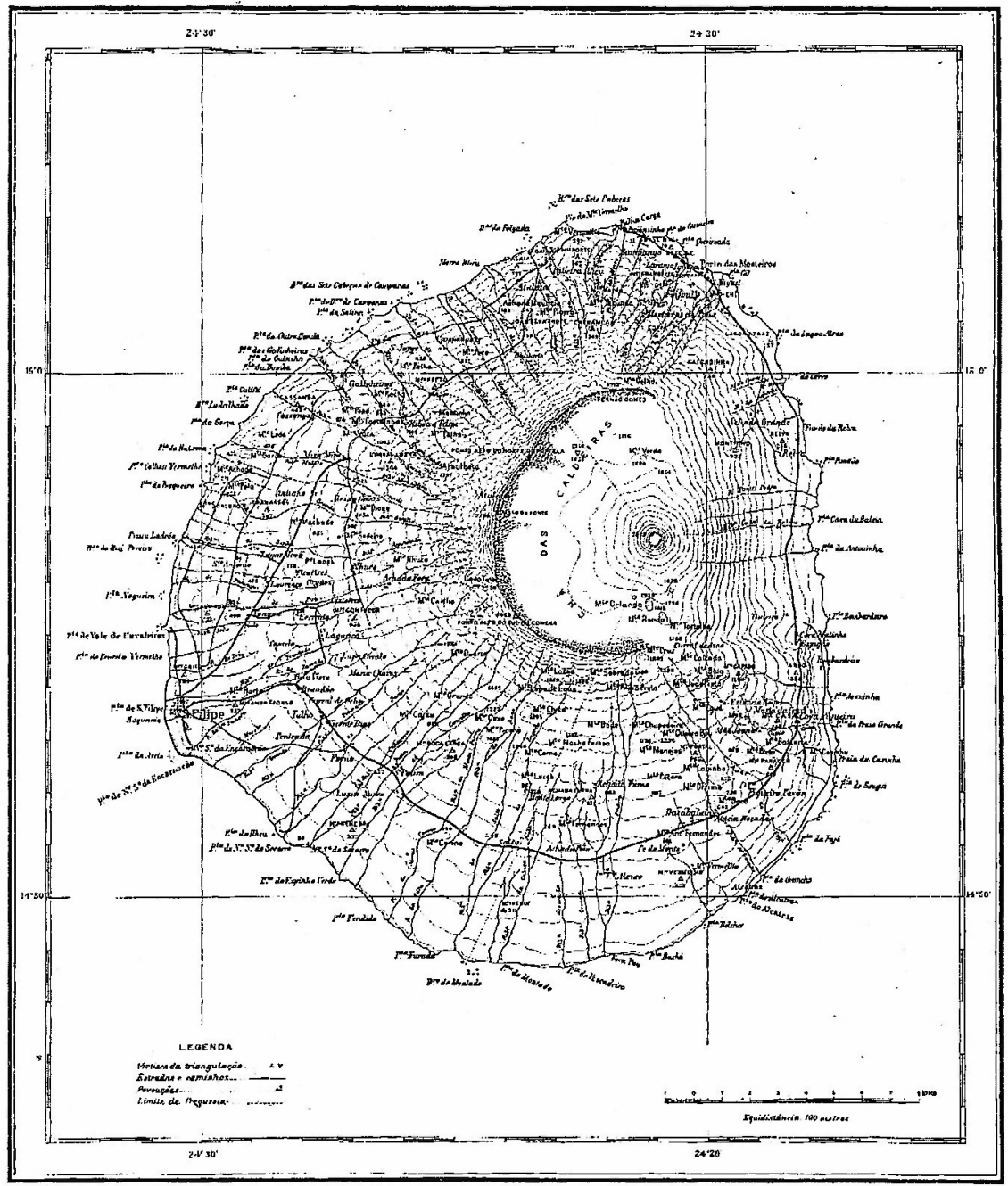

Fig. 3 - Mapa da ilha do Fogo. Adaptado do mapa de escala 1:150000 da Junta de Investigações do Ultramar (1954). lávicos associados. Coloca-se excentricamente dentro da caldeira, enquanto o flanco Leste desce directa e abruptamente para o mar. Em relação com o grande cone secundário observam-se, no flanco e no sopé, vários cones adventícios, dos quais são testemunhos os cones construidos com a erupção de 1951 (Monte Orlando e Monte Rendall) e o cone edificado pela erupção de 1995 (Monte Mota Gomes).

\section{Estrutura vulcânica e tectónica}

A principal estrutura vulcânica da ilha do Fogo é a própria ilha, isto é, um grande aparelho vulcânico de forma aproximadamente circular, constituido principalmente por derrames basálticos e por produtos piroclásticos em menor escala (A.B. SILVEIRA, J. MADEIRA e A. SERRALHEIRO, 1997).

No topo do vulcão existe uma caldeira com cerca de $8 \mathrm{Km}$ de diâmetro máximo a que falta o bordo oriental. Trata-se de uma estrutura gerada por colapso da parte central do aparelho vulcânico. $O$ bordo interno da caldeira apresenta-se abrupto, com um comando máximo de cerca de 1100 metros; esta escarpa tem a designação de Bordeira.

No interior da depressão, a Chã das Caldeiras, edificou-se o Vulcão do Pico, com o ponto mais alto, como vimos, a 2829 metros de altitude. Este aparelho resultou de intensa actividade vulcânica, subsequente ao colapso da caldeira. As erupções mais recentes, várias delas históricas, entre as quais a de Abril-Maio de 1995, ocorreram na base do Vulcão.

No respeitante às estruturas tectónicas anteriormente conhecidas na ilha do Fogo, J. B. BEBIANO (1932) representa, no Esboço Tectónico do Arquipélago, uma falha de direcção N-S, entre a ilha de S. Nicolau e a ilha do Fogo. MACHADO e ASSUNÇÃO (1965) retomaram a ideia da existência de uma falha $\mathrm{N}-\mathrm{S}$, em posição axial à ilha do Fogo, representando-a na carta geológica pelo alinhamento dos cones Monte 
Quebra-Buli, Monte Escora e Monte Vermelho. Na opinião destes autores, a movimentação na falha, com abatimento do bloco oriental, seria responsável pela assimetria da ilha e teria provocado o afundamento do bordo Leste da caldeira, o qual teria sido posteriormente fossilizado pelos derrames recentes.

\section{Estrutura tectónica}

Na sequência dos estudos realizados foi possível propôr um modelo estrutural para a ilha do Fogo (Fig. 4), com base na identificação e caracterização das principais estruturas de origem vulcânica, tectónica e gravítica que foram reconhecidas durante duas missões geológicas efectuadas em 1995. Esses estudos, tendentes à caracterização tectónica da ilha do Fogo, permitiram a identificação de três sistemas de falhas principais, com direcções de NW-SE a WNW-ESE, N-S e NNE-SSW.

Paramelhor elucidaçãodescrevem-se os principais acidentes identificados - a falha Sambango-Monte Vermelho, as estruturas tectónicas reconhecidas na Chã das Caldeiras e a falha PortelaCova Figueira.

Falha Sambango-Monte Vermelho

Trata-se de uma falha de direcção $\mathrm{N}-\mathrm{S}$, sugerida por J. B. BEBIANO (1932) e por MACHADO e ASSUNÇÃO (1965). Os estudos realizados por A.B. SILVEIRA, J. MADEIRA e A. SERRALHEIRO (1997) levaram a considerar a existência de uma zona de falha que se designou falha Sambango-Monte Vermelho (Fig, 4/ S-MV). Todavia, afirmam os Autores acima referidos que a inexistência do bordo Leste da caldeira da ilha do Fogo não pode ser explicada apenas por movimentação nesta falha uma vez que não há evidências morfológicas de uma grande escarpa de falha, quer a Norte, quer a Sul da caldeira, nas áreas que não foram fossilizadas pelos

Fig. 4 - Esboço estrutural da ilha do Fogo. Extraído de A. BRUM da SILVEIRA. J. MADEIRA e A. SERRALHEIRO (1997). derrames recentes. Para explicar a ausência da bordeira a Leste outros mecanismos poderão ser invocados, como, por exemplo, o colapso por escorregamento gravítico.

Estruturas tectónicas reconhecidas na Chã das Caldeiras

A falha do Monte Becoé definida pelo alinhamento de várias bocas eruptivas de direç̧ão aproximada N25E a N30E (Fig. 4/MB), relacionadas com a erupção de 1995. A falha prolonga-se para SW, estando expressa na cratera do Monte Beco por um ressalto morfológico. Este degrau, voltado para SE e com comando aproximado de 1,5 metros, corresponde, provavelmente, a uma escarpa de falha directa relacionada com anteriores rupturas superficiais na falha de Monte Beco (B. SILVEIRA, et al,, 1997).

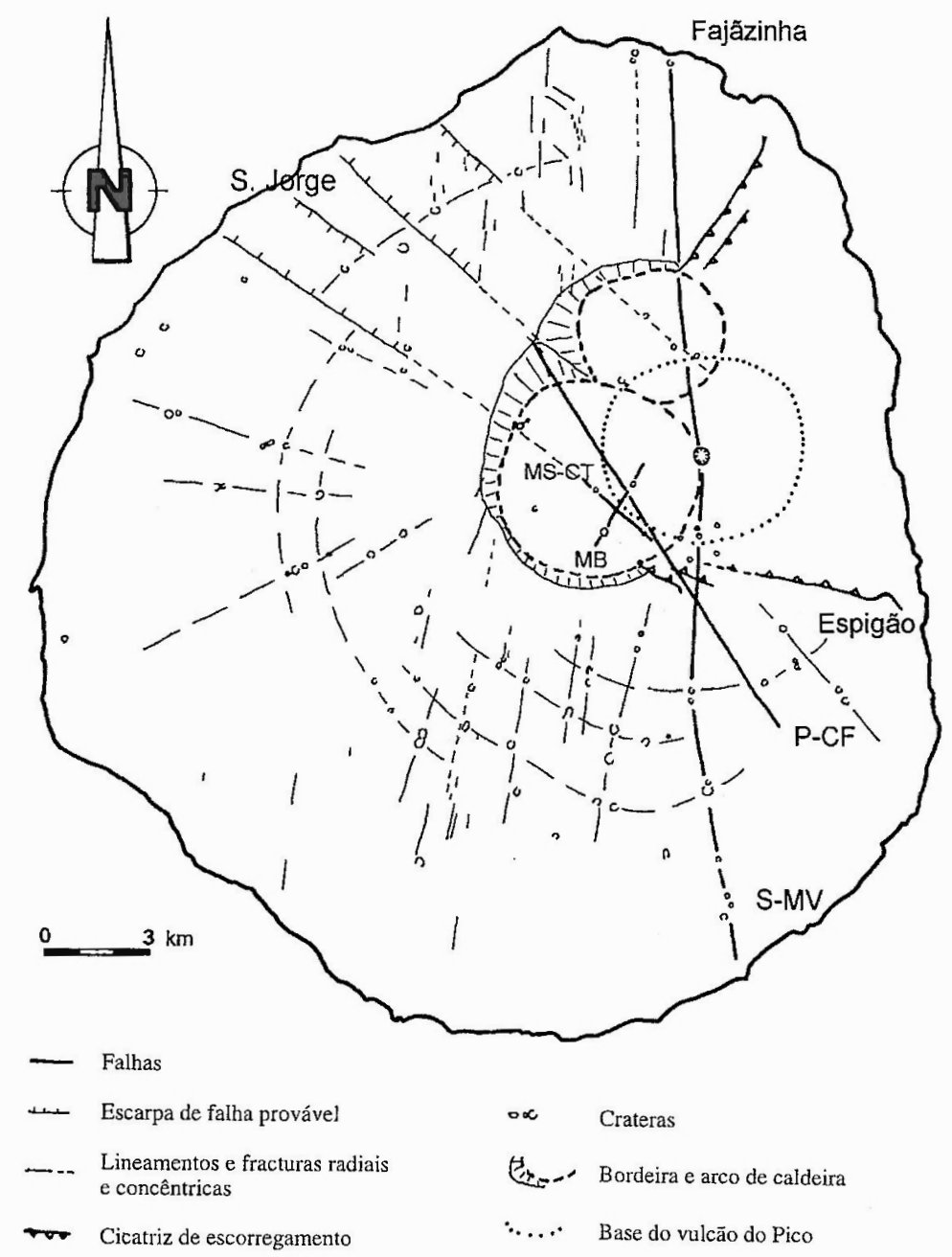


A falha Monte Saia-Cova Tina é identificada através de um plano de falha com direcção N60-65W e subvertical (Fig. 4/MS-CT). A designação atribuida a esta estrutura resulta da localização dos cones vulcânicos do Monte Saia e da Cova Tina, no prolongamento para WNW e ESE do plano de falha observado, sugerindo que possam ter a sua localização controlada por aquele acidente (B. SILVEIRA et al., 1997).

\section{Falha Portela-Cova Figueira}

A análise geomorfológica e fotogeológica sugere a existência de uma zona de falha orientada segundo a direcção NW-SE, no alinhamento Portela-Curral d'Asno-Cova Figueira (Fig. 4/ P-CF). Esta estrutura é designada por falha Portela-Cova Figueira e está marcada no terreno por uma intensa fracturação que se pode observar na Bordeira, nas zonas de Cova Tina e Portela. $O$ alinhamento de cones na região de Estância de Roque-Cova Figueira, a SE, e o alinhamento de várias linhas de água de traçado rectilíneo na região de Campanas-S. Jorge, a NW, assinalam o traçado da falha Portela-Cova Figueira (B. SILVEIRA et al., 1997).

\section{Riscos vulcânicos - o caso do Vulcão do Fogo}

\section{Introdução}

O estudo da ilha do Fogo e, particularmente, os estudos realizados sobre o seu vulcanismo, com o registo de 26 erupções, permitem-nos considerar como elementos de risco vulcânico os seguintes:
a) configuração da ilha;
b) estrutura vulcânica e tectónica;
c) reabertura de focos emissores;
d) queda de cinzas e de poeiras vulcânicas;
e) libertação de gases vulcânicos;
f) ocupação de áreas por lavas;
g) possível contaminação da água;
h) sismos associados ao vulcanismo.

A actividade eruptiva na ilha do Fogo eclodida a 2 de Abril de 1995 e que se prolongou até ao dia 26 de Maio de 1995 provocou sérias preocupações, principalmente em Chã das Caldeiras, localidade incontestavelmente de maior risco vulcânico na ilha e que, por isso, as populações estiveram sujeitas a sérios riscos. Daí, justificável a evacuação dessas pessoas para locais de menor risco vulcânico.

Todavia, deve-se assinalar que a ilha do Fogo é um gigantesco vulcão, ainda activo, que necessita de uma monitorização sismovulcânica com um sistema de vigilância alargado às vertentes da geofísica, da geodesia e da geoquímica.

Relativamente à saúde pública, a erupção vulcânica de 1995 criou sérios riscos, com graves repercussões nas populações de Boca Fonte, Portela e Bangaeira, aglomerados populacionais da localidade da Chã das Caldeiras, antes do início da actividade eruptiva. Porém, o aglomerado populacional da Boca Fonte foi dizimado pelo movimento do "rio" de lava que constituiu a fase efusiva ocorrida no período de 2 a 22 de Abril de 1995 e que deu origem ao campo de lavas "aa" (Fot. 1).

Esses riscos para a saúde pública resultaram, essencialmente, da queda de cinzas e de poeiras

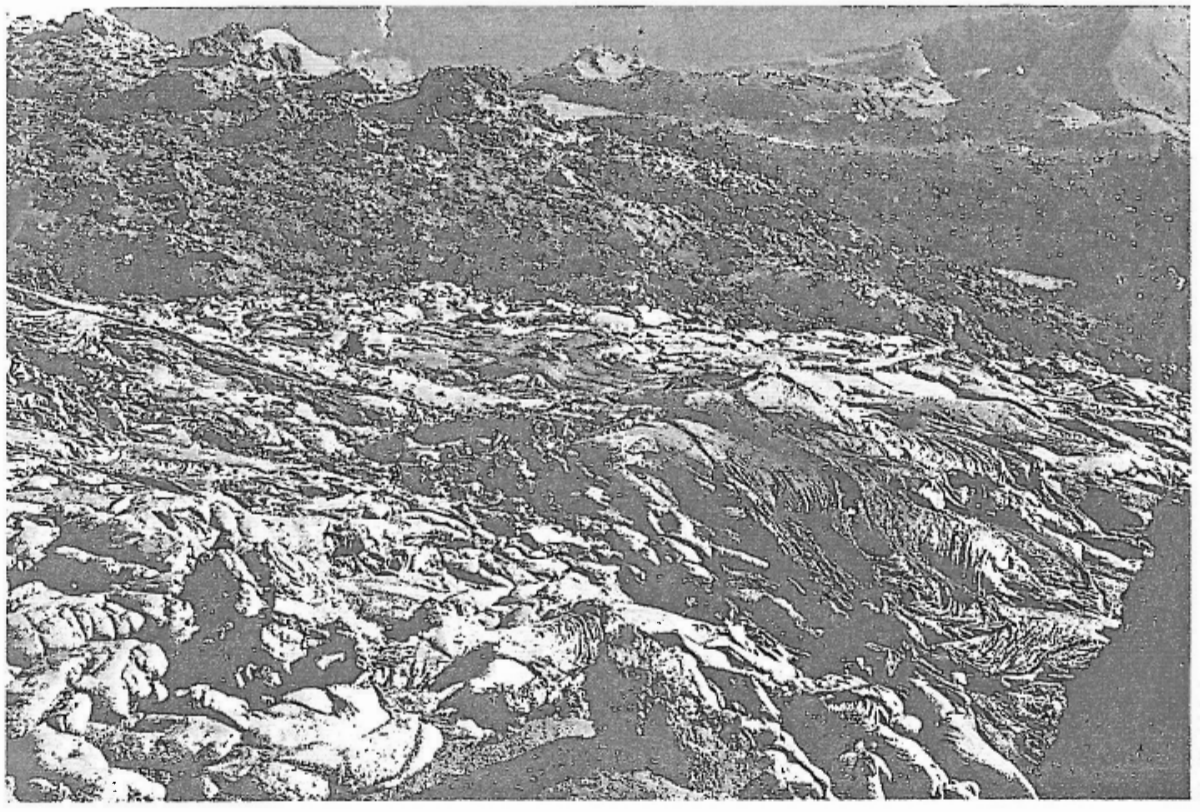

Fot. 1 - Campo de lavas "aa", em cima e "pahoehoe", em baixo (erupção do vulcão do Fogo, 1995). 


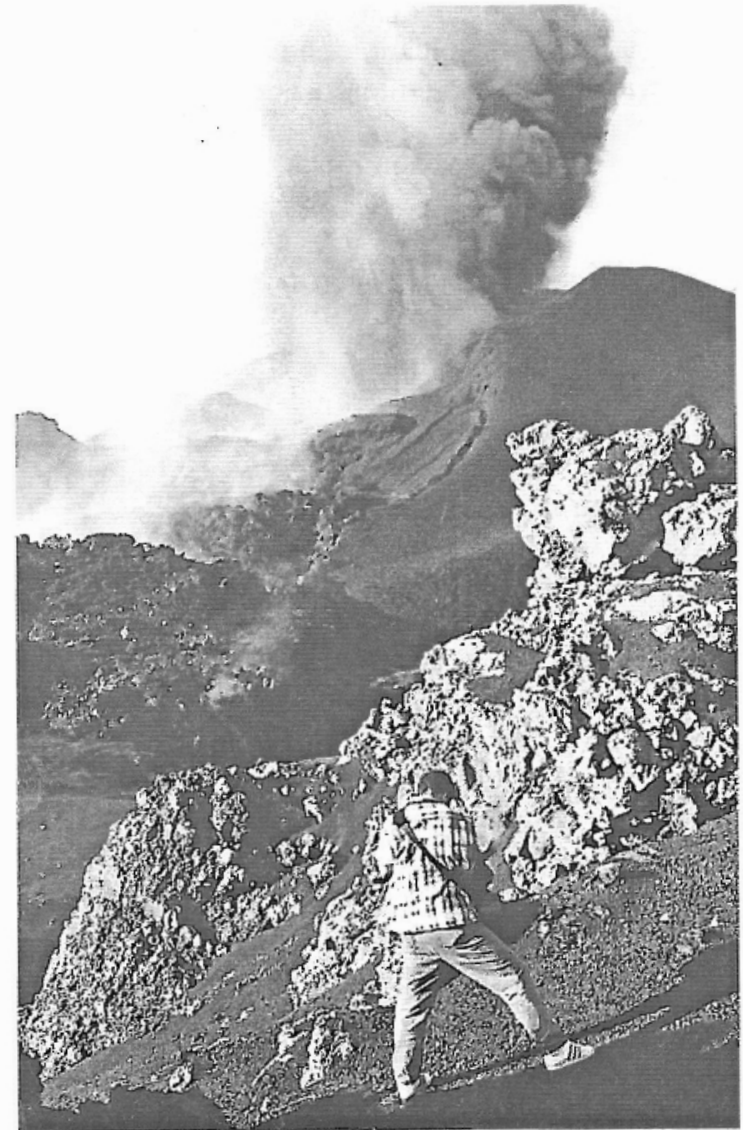

Fot. 2 - Coluna eruptiva (erupção do vulcão do Fogo, 1995).

vulcânicas e da libertação de gases vulcânicos durante a fase explosiva que marcou o período de 2 a 22 de Abril de 1995, tendo originado uma "coluna eruptiva" que alcançou cerca de 6000 metros de altitude máxima (Fot. 2).
A queda de cinzas e de poeiras vulcânicas criou pânico nas primeiras horas do dia 3 de Abril, isto é, imediatamente a seguir ao início da erupção vulcânica, nas localidades próximas do vulcão e na região Leste da ilha, concretamente, nas localidades de Corvo, Achada Furna e Relva. As populações procuraram refúgio nos Mosteiros, temendo o pior, à semelhança do que acontecera na erupção vulcânica de 1951, quando as lavas tomaram a direcção Leste descendo para o mar. Os habitantes das localidades de Tinteira, Cova Matinho, Cova Figueira, Estância Roque e Figueira Pavão, também da parte Leste da ilha, procuraram refúgio em S. Filipe.

Duas equipas do Departamento de Geociências da Universidade dos Açores conjuntamente com a equipa do Núcleo de Coordenação das Actividades Geofísicas de Cabo Verde realizaram trabalhos que visaram determinar a possível inquinação da água para consumo público, o estudo dos gases vulcânicos e da queda de material piroclástico, bem como de outras causas indirectas para a saúde pública.

\section{Riscos de contaminação da água parao consumo público}

Procurou-se saber se a água utilizada para consumo público tinha sido afectada pela erupção vulcânica, pois que poderia acarretar sérios riscos para a saúde pública das populações de toda a ilha do Fogo. Foram, por isso, feitas colheitas de água na zona do Monte Vermelho, que abastece as populações da área dos Mosteiros (Amostras - Fogo 1, 2 e 3) e na zona da Achada Malva, que abastece o Concelho de S. Filipe (Amostras - Fogo 4 e 5).

Felizmente, e apesar de não termos os resultados completos das análises, com os resultados obtidos
Tabela 1 - Resultados relativos às determinações efectuadas nas captações dos Mosteiros e de S. Filipe

\begin{tabular}{lccccccccc}
\hline Amostra & Tmp ${ }^{\circ} \mathrm{C}$ & $\begin{array}{c}\text { Cond. } \\
\text { uSem-1 }\end{array}$ & pH & Eh & $\begin{array}{c}\text { Ox. Dis. } \\
\mathrm{mg} / \mathrm{l}\end{array}$ & $\begin{array}{c}\mathrm{CO}_{2} \\
\mathrm{mg} / \mathrm{l}\end{array}$ & $\begin{array}{c}\mathrm{Alc} . \\
\mathrm{mg} / \mathrm{l}\end{array}$ & $\begin{array}{c}\mathrm{Cl} \\
\mathrm{mg} / 1\end{array}$ & $\begin{array}{c}\mathrm{H}_{2} \mathrm{~S} \\
\mathrm{mg} / \mathrm{l}\end{array}$ \\
\hline Fogo 1 & 22,8 & 198,5 & 7,70 & 143,6 & $-0,21$ & 7,8 & 78 & 23,5 & n.d. \\
Fogo 2 & 23,1 & 193,3 & 7,53 & 179,0 & $-0,21$ & 4,2 & 54 & 23,5 & n.d. \\
Fogo 3 & 22,7 & 212,0 & 7,60 & 189,4 & $-0,26$ & 2,8 & 55 & 27,0 & n.d. \\
Fogo 4 & 26,8 & 368,0 & 8,27 & 233,6 & $-0,19$ & 4,0 & 144 & 19,2 & n.d. \\
Fogo 5 & 26,5 & 357,0 & 8,31 & 193,2 & $-0,19$ & 4,0 & 153 & 18,5 & n.d. \\
\hline
\end{tabular}

n.d. - não detectado.

\begin{tabular}{|c|c|c|c|c|c|c|}
\hline \multirow[b]{2}{*}{ Amostra } & & \multicolumn{5}{|c|}{ Moles \% } \\
\hline & & $\mathrm{CO}_{2}$ & $\mathrm{H}_{2} \mathrm{~S}$ & $\mathrm{~N}_{2}$ & $\mathrm{Ar}$ & $\mathrm{O}_{2}$ \\
\hline Fumarola (fissura) & (a) & 49,5 & n.d. & 39,9 & 0,47 & 10,1 \\
\hline Fumarola (lava) & (a) & 38,8 & n.d. & 48,4 & 0,57 & 12,2 \\
\hline Ar atmosférico & & 1,95 & - & 77,6 & 0,92 & 19,5 \\
\hline
\end{tabular}

Tabela 2 - Análises químicas das emanações gasosas e do ar atmosférico

(a) Os resultados analíticos referem-se ao total da fase seca. n.d. - não detectado. 
em componentes como o $\mathrm{CO}_{2}$ e $\mathrm{o}_{2} \mathrm{~S}$ pôde concluirse que o fenómeno em causa não terá afectado os aquíferos alvo de estudo (in "Riscos para a saúde pública associados à erupção de 2 de Abril de 1995 na ilha do Fogo").

\section{Riscos provocados pela libertaçãode gases vulcânicos}

Nos primeiros dias de actividade eruptiva foi deveras in tensa a libertação de gases, o que deixou a Chã das Caldeiras em sérios riscos para a saúde pública. Durante esse período de tempo, algumas das pessoas que se encontravam nas proximidades do foco eruptivo principal apresentaram sintomas resultantes da inalação de gases tóxicos, tais como dores de cabeça, irritação da garganta, com tosse, irritação na vista e na pele e sinais de indisposição, tendo alguns casos exigido assistência médica.

Mais tarde, quando a direcção e a intensidade dos ventos impediram a ascenção das colunas de gases, geraram-se núvens descendentes que se propagaram junto ao solo e atingiram os limites da caldeira em escassos minutos. Nessa altura, um intenso odor a enxofre invadiu a atmosfera no interior da caldeira, dificultando a normal circulação das pessoas. Em determinados períodos assistiu-se à formação de densas núvens de gases juntoà superfície da Chã das Caldeiras associadas a uma diminuição da energia da emissão, mas também a condições atmosféricas que dificultavam a sua ascenção e dispersão (E. CORREIA, 1997).

Nesses períodos, o Núcleo de Coordenação das Actividades Geofísicas de Cabo Verde deu instrução às Forças Armadas Cabo-verdianas para que, por razões de segurança e de protecção à saúde pública, ficasse interdita a circulação de visitantes no interior da Chã das Caldeiras, o que foi prontamente cumprido já que as duas instituições trabalharam sempre em estreita colaboração.

Os resultados obtidos no estudo da desgasificação através dos solos apontaram para a quase inexistência de outras zonas de libertação de gases no interior da Chã das Caldeiras para além do centro eruptivo.

Em termos de saúde pública, os resultados obtidos para a concentração do $\mathrm{CO}_{2}$ no ar atmosférico nas proximidades do cone de escórias activo apenas excederam ligeiramente os valores estipulados para o limite de segurança admissível $(0,5$ moles \% BLONG, 1984). Não obstante, várias pessoas sentiram dores de cabeça, irritação na garganta, na vista e na pele e sinais de indisposição, tendo-se inclusivamente registado alguns casos que exigiram assistência médica (GASPAR et al., 1995).

No estudo da desgasificação do $\mathrm{CO}_{2}$ através dos solos não se obtiveram concentrações superiores a $2 \%$.
No sentido de se avaliar o risco associado à emanação de gases vulcânicos no interior da caldeira fez-se a amostragem de fumarolas e do ar atmosférico nas proximidades do cone de escórias activo e o estudo da desgasificação do $\mathrm{CO}_{2}$ através dos solos.

\section{Riscos causados pela queda de cinzas e de poeiras vulcânicas}

A queda de cinzas e de poeiras vulcânicas, mesmo nas primeiras horas da erupção, obrigou à fuga das pessoas, especialmente, da região Leste da ilha. As dos povoados de Corvo, Relva e Achada Grande seguiram para Mosteiros, enquanto as das povoações de Tinteira, Cova Matinho, Cova Figueira, Estância Roque e Figueira Pavão se dirigiram para Patim e S. Filipe.

De acordo com as informações do médico colocado nos Mosteiros, foram detectados inúmeros casos de conjuntivite devido à camada finíssima de poeira que ficou no ar por muito tempo, particularmente nas zonas de Achada Grande, Relva e Corvo. Porém, apesar de algumas preocupações por parte das autoridades sanitárias, não se verificou o aumento de casos de infecções respiratórias agudas, como era de esperar, naquelas localidades.

O mesmo não teria acontecido com as populações das outras zonas que se refugiaram em S. Filipe, especialmente com as crianças.

Com a criação dos quatro campos de acolhimento (S. Filipe, Patim, Achada Furna e Mosteiros Trás), nos quais se instalaram os desalojados ${ }^{(1)}$, verificou-se o maior número de consultas dadas que foram de doenças respiratórias agudas e dermatoses que, directa ou indirectamente, poderiam ter sido causadas pelas cinzas e poeiras.

\section{Riscos de ocupação de áreas cultivadas por lavas}

A lava resultante da erupção de 1995 destruiu o aglomerado populacional da Boca Fonte, que ficou completamente coberto, com todas as suas casas destruidas, num total de treze, incluindo a Cooperativa de vinhos. Foi igualmente cortado o acesso motorizado à Chã das Caldeiras.

O solo da Chã das Caldeiras é das melhores terras agrícolas da ilha do Fogo. Com uma área de 2950 ha, 287 dos quais cultivados (10\%), tinha aptidão para aumentar este último número. Perdeu-se cerca de $17 \%$ (48,8 ha) da terra arável, representando a área mais fértil para a produção de batata, feijão e mandioca,

(1) S. Filipe albergou um máximo de 731 pessoas e um mínimo de 616, Patim um máximo de 127, Achada Furna um máximo de 185 e Mosteiros Trás sempre 95. 
com a possibilidade de duas produções por ano (J. CORREIA, et al., 1997). Todavia, apenas 8,5\% das famílias perderam toda a sua terra; $41,2 \%$ perderam só algum terreno agrícola.

Vinha, frutas diversas, batata, feijão, mandioca e leguminosas são culturas que se dão muito bem com as condições climáticas da Chã das Caldeiras. Por conseguinte, a perda duma parte de terra arável foi um prejuizo irrecuperável a curto e médio prazos. Cerca de $50 \%$ da área agricultável é coberta pela cultura fruteira (videiras, marmeleiros, macieiras, figueiras, etc.), enquanto os restantes $50 \%$ são cobertos com culturas como feijão, batata, mandioca e essências florestais.

A área total coberta pelas escoadas é de $4,04 \mathrm{Km}^{2}$, enquanto o cone de escórias ocupa $0,65 \mathrm{Km}^{2}$.

\section{Riscos sísmicos associados ao vulcanismo}

Portugal enviou à ilha do Fogo pessoal de instituições especializadas no domínio da Geofísica, devendo destacar-se o Instituto Geofísico Infante D. Luís da Universidade de Lisboa, o Instituto de Meteorologia e o Instituto Superior Técnico, com a finalidade de procederem à vigilância da sismicidade durante o período inicial da actividade eruptiva e que asseguraram um conjunto de estações sísmicas dispostas como uma rede em torno do vulcão e, também, em locais bem determinados da ilha.

Especialistas doInstituto Superior Técnico permaneceram na ilha por mais tempo, tendo ajudado na instalação da Rede de Vigilância Geofísica do Vulcão do Fogo, que funciona nas instalações do Laboratório de Engenharia de Cabo Verde, na cidade da Praia, que tem recebido com regularidade os sinais das estações sísmicas instaladas nas ilhas do Fogo e da Brava de modo a precaver-se de qualquer ocorrência sismo-vulcânica.

De acordo com L. MATIAS et al. (1997), a maioria dos dados obtidos consiste em sismos de alta frequência, de origem tectónica. A distribuição de epicentros mostra uma concentração da actividade sísmica nas regiões Sul e Sueste da ilha, em zonas onde trabalhos de campo identificaram várias falhas activas (B. SILVEIRA et al., 1997). Conclui-se que a actividade registada não se encontra directamente relacionada com a erupção de lavas na boca do vulcão. A origem tectónica da sismicidade significa que ela se deve à reactivação de falhas sob a acção da redistribuição de tensões no interior do edifício vulcânico.

\section{Referências bibliográficas}

BEBIANO, J. B. (1932) - A Geologia do Arquipélago de Cabo Verde. Comunicações dos Serviços Geológicos de Portugal. XVIII, Lisboa, 275 p.

BLONG, R. J. (1984) - Volcanic Hazards. A sourcebook on effects of eruptions. Academic Press, 424 p.

CORREIA, E. (1997) - "Riscos de queda de cinzas e concentração de gases associados às condiç̃̃es atmosféricas na Ilha do Fogo". A erupção vulcânica de 1995 na llha do Fogo, Cabo Verde, Lisboa, IICT, p. 279-291.

CORREIA, J., ARAÚJO, M. G. M. e NASCIMENTO, J. (1997) "Impactos sócio-económicos da erupção de 1995 na Ilha do Fogo". A erupção vulcânica de 1995 na llha do Fogo, Cabo Verde, Lisboa, IICT, p. 325-334.

GASPAR, J.L., FERREIRA, T., COUTINHO, R., QUEIROZ, G., BOTELHO, S., FRAGOSO, F., GOMES, A. M., RAMOS, M., DELGADO, J. e AZEVEDO, N. (1995) - Riscos para a saúde pública associados à erupção de 2 de Abril de 1995 na Ilha do Fogo (Cabo Verde). Relatório do Departamento de Geociências da Universidade dos Açores, Ponta Delgada, 24p.

GOMES, A. Mota e RODRIGUES, R.L. (1997) - "Protecção civil provocada pela erupção vulcânica de 1995 na Ilha do Fogo o serviço de Protecção Civil". A erupção vulcânica de 1995 na Ilha do Fogo, Cabo Verde, Lisboa, IICT, p. 335-344.

MACHADO, F. e ASSUNÇĀO, C. T. (1965) - "Carta Geológica de Cabo Verde (na escala de 1: 100 000). Notícia explicativa da folha da Ilha do Fogo - Estudos petrográficos". Garcia de Orta, 13 (4), p. 597-604.

DEPARTAMENTO DE GEOCIÊNCIAS DA UNIV. AÇORES E DEPARTAMENTO DE GEOCIÊNCIAS DO INST. SUP. EDUCAÇÃO DE CABO VERDE (1995) - Riscos para a Saúde Pública associados à erupção de 2 de Abril de 1995 na Illha do Fogo, Cabo Verde. Maio de 1995, Relatório inédito.

MATIAS, L., CRUZ, J., PENA, J. A., MARTINS, I. e SENOS, M. L. (1997) - "A sismicidade registada na Ilha do Fogo durante os primeiros dias de actividade do vulcão na erupção de Abril de 1995". A erupção vulcânica de 1995 na llha do Fogo, Cabo Verde, Lisboa, IICT, p. 13-32.

RIBEIRO, O (1960) - A Ilha do Fogo e as suas erupções. Junta de Investigações do Ultramar, Lisboa, 319 p.

SILVA, L.C. (1992)-Localização etipos de magnetismos existentes em Cabo Verde.

SIL VEIRA, A.Brum da, MADEIRA J. eSERRALHEIRO, A (1997) - "A estrutura da Ilha do Fogo, Cabo Verde". A Erupção Vulcânica de 1995 na llha do Fogo, Cabo Verde, Lisboa, IICT, p. 63-78. 
